\title{
NEW RAILWAY TUNNELS AND THEIR CONSTRUCTION METHOD AS WELL AS THEIR IMPACT TO TRAIN OPERATION
}

\begin{abstract}
As the modernisation of the cities, railway road construction and modernisation of existing lines are demanded during the past decades more than before. Demand of short travel time is one the reasons that we redesign of existed railway roads and modernisation process. Tunnel construction is one the ways that we can shorten travel time in the existing railway roads. In this study, we introduced one of the commonly used tunnel construction methods, New Austrian Tunnelling Method (NATM), and some of important points of that method regarding tunnel excavation and bearing capacity of excavation support system. Furthermore, we gave some information about some tunnels which shortens the travel time and some tunnel project examples which are constructed with this method. The main purpose of construction of all these tunnels are to shorten the travel time of the existing railway line due to increasing on population and urbanization.
\end{abstract}

Keywords: railways, tunnels, NATM, operation

\author{
Murat Kalender ${ }^{1}$ \\ ${ }^{1}$ Civil Engineer, M.Sc., SWS Global A.S,,TURKEY.; kalendermurat01@gmail.com \\ Martin Vojtek ${ }^{2}$ \\ ${ }^{2}$ University of Pardubice, Faculty of Transport Engineering, Department of Transport Technology \\ and Control, Studentska 95, 53210 Pardubice, Czechia; martin.vojtek@upce.cz
}

\section{Introduction}

Number of railway road construction has been increasing during the past decades with the demand of short travel time as a result of increasing on population and urbanization. One of the ways for providing shorter travel time is changing route of the railway according to geographical and geotechnical conditions.

Due to some economical and technological reasons, routes of railways have been limited to construct before in easier geotechnical conditions such as implementing the route on the side of the mountains without any tunnel design, lack of proper tunneling machines etc.

In this study, we aimed to introduce one of the tunnel construction methods, New Austrian Tunneling Method (NATM) and give some constructed and under construction tunnel project examples from Czech Republic and Slovakia as examples of shortening travel time in railway operation.

\section{NATM tunnel construction method}

Construction of railway tunnels are one of the efficient ways to shorten travel time and reach out far distances due to enlargement of cities. One of the tunnel construction methods is called NATM and it was used in many tunnel construction projects around the world (Aygar\&Gokceoglu 2020, Xu\&Huang 2004). Rabcewicz is the principle inventor of NATM and he has been explained the method as an international recognition in 1964 (Rabcewicz 1964, Rabcewicz 1965, Rabcewicz\&Golser 1973). Furthermore, it was developed by many scientists in the following years. Historical background of NATM, definitions and development of it according to different scientists and some teoretical and technical explanatios about it have been gathered together very well by Karakus (Karakus\&Fowell 2004).
One of the important point in NATM type of tunnel construction is soil-structure interaction which is between disturbed area around tunnel excavation (protective zone) and bearing capacity of the excavation support system (skin resistance) (Rabcewicz 1964). Mathematical definition of this interaction was described by FennerTalobre and Kastner and can be seen in Rabcewicz (1964) as:

$$
p_{\mathrm{i}}=-c \cot \varphi+p_{0}[c \cot \varphi+(1-\sin \varphi)] \frac{r^{\frac{2 \sin \varphi}{1-\sin \varphi}}}{R}
$$

Neglecting the value of cohesion, the equation can be simplified as:

$$
p_{\mathrm{i}}=p_{0}[c \cot \varphi+(1-\sin \varphi)] \frac{r^{\frac{2 \sin \varphi}{1-\sin \varphi}}}{R}=n p_{0}
$$

where;

$p_{i}$ : skin resistance,

c:cohesion,

$\varphi$ : angle of internal friction,

$\mathrm{R}$ : radius of the protective zone,

$\mathrm{r}$ : radius of cavity,

$\mathrm{p}_{0}: \gamma \mathrm{H}$

$\mathrm{H}$ : overburden,

This relation can be seen schematically in Fig. 1 below. 


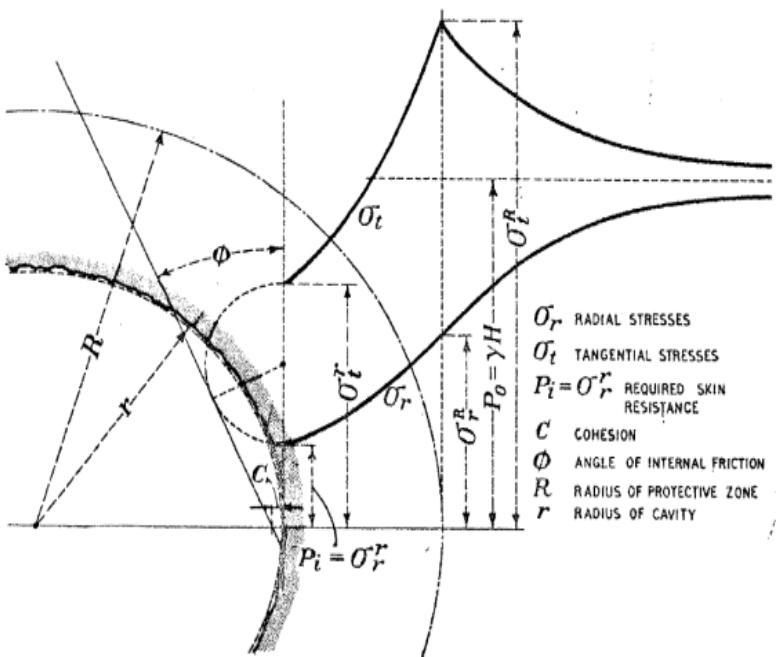

Fig. 1. Schematic representation of stresses around a circular cavity with hydrostatic pressure (quoted by Rabcewicz, 1964; after Kastner)

There is a relationship between skin resistance and deformation due to excavation shown in Fig. 2 (Rabcewicz, 1973). It can be seen that if a support system is applied in a short time period after the cavity opening, it will obviously prevent most of the deformation which will cause that the support system will carry a big amount of load. If the support system is applied in the right time of displacement, then it will carry the minimum amount of load (see Fig. 2).

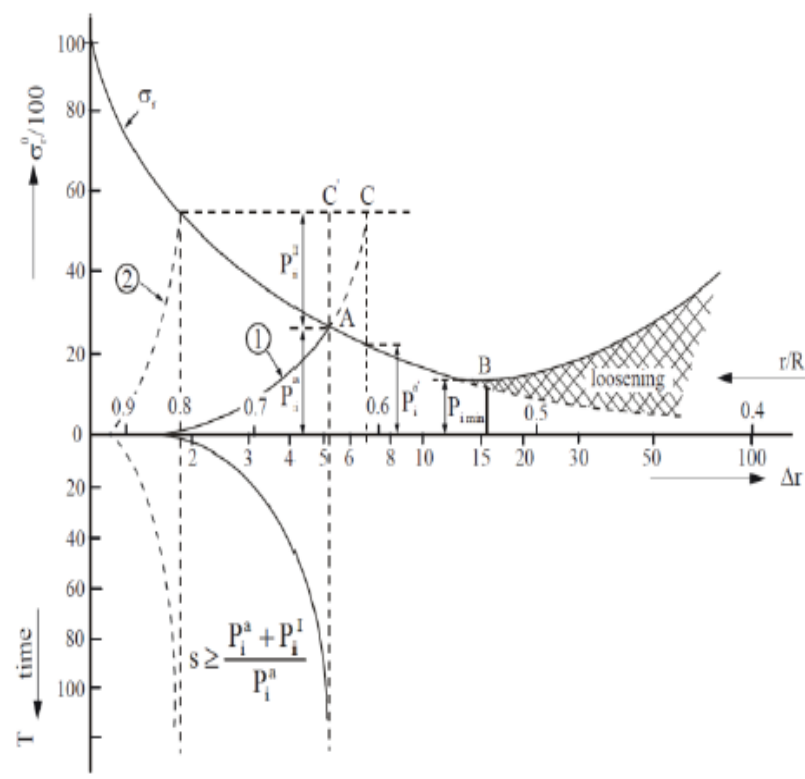

Fig. 2. Ground-support interaction curve (after Fenner \& Pacher, quoted by Rabcewicz 1973)

\section{New tunnel examples on existing railway lines}

There are some railways which route have been changed with new tunnels in Czech Republic. One of them is tunnel Ejpovice which locates in railway line Rokycany - Pilsen as it can be seen in Fig. 3 below.

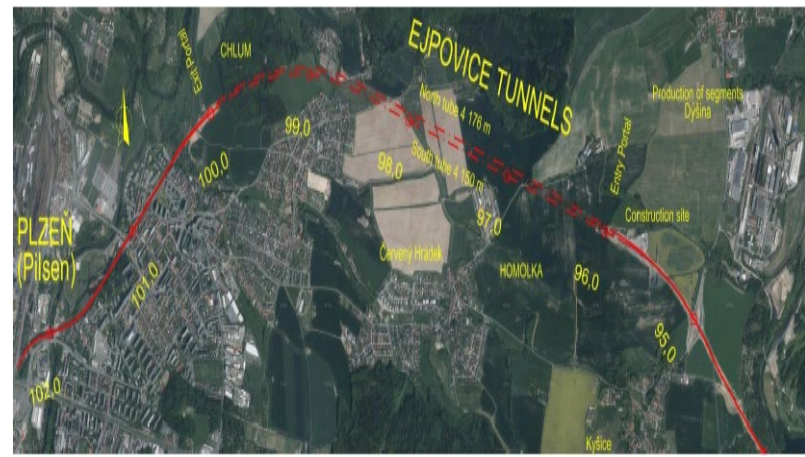

Fig. 3. Ejpovice tunnels (Marek M. et al.)

Due to the geological and geotechnical conditions, tunnels can be excavated in different soil types and in different geological soil profiles. NATM is a suitable method to apply tunnel construction in different soil types. In Fig. 4 it can be seen below that the profile of southern tunnel of Ejpovice tunnels has different soil types.

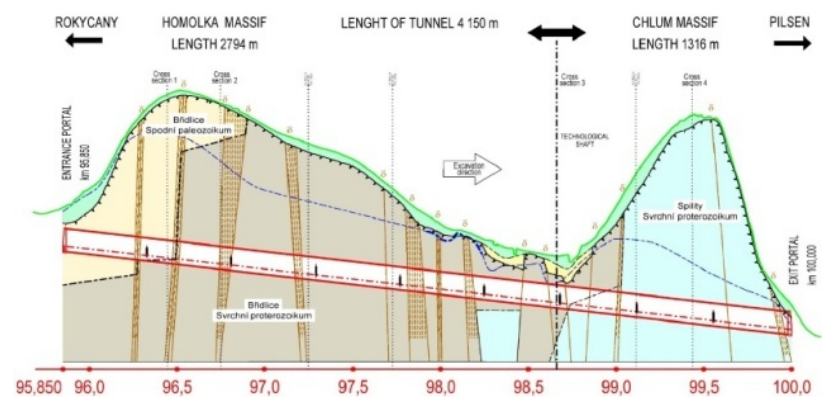

Fig. 4. Longitutional section of southern Ejpovice tunnel (Marek M. et al.)

Length of southern and northern tunnels are $4176 \mathrm{~m}$ (4 $134 \mathrm{~m}$ bored) and $4150 \mathrm{~m} \mathrm{(4} 110 \mathrm{~m}$ bored) respectively (Marek M. et al.). The planned speed limit is $160 \mathrm{~km} / \mathrm{h}$ (Marek M. et al.), which is the maximum allowed speed limit in Czech Republic as indicated in Network Statements of Czech Republic 2022, and prospectively $200 \mathrm{~km} / \mathrm{h}$ which was tested succesfully as indicated in annual report of Sprava Zeleznic, which is Railway Administration of Czech Republic, in 2020 and it is the current longest railway tunnel in the country (Annual report, Sprava Zeleznice, Czech Republic 2020).

There is also another tunnel which name is Turecký Vrch railway tunnel and it was constructed in Slovakia as a result of modernisation of main railways. A schematic representation of the tunnel can be seen in Fig. 5 below. 


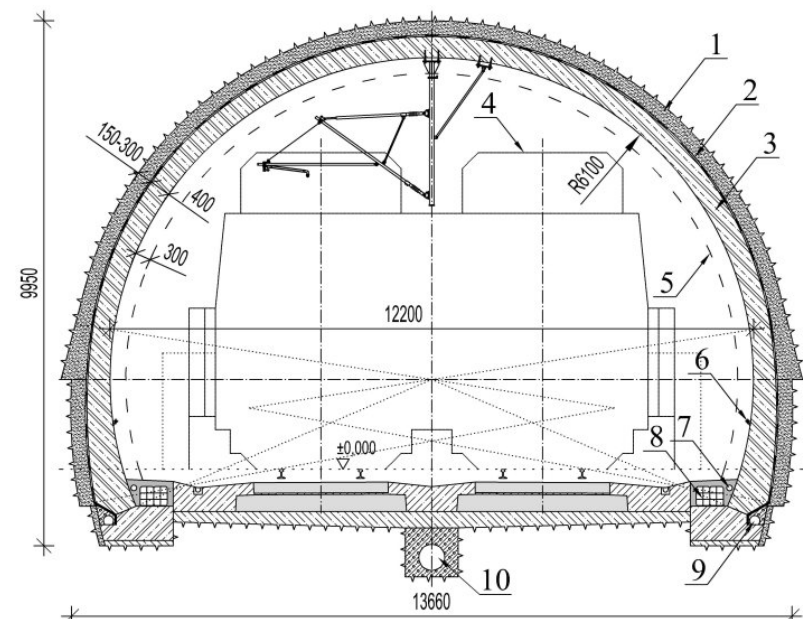

Fig. 5. Schematic representation of Turecký Vrch railway tunnel (Metroprojekt)

Total lenght of the tunnel is $1775 \mathrm{~m}$ (1740 m bored) with $35 \mathrm{~m}$ cut-and-cover sections and maximum overburden depth is $100 \mathrm{~m}$. This tunnel was constructed with NATM which was mentioned above and for 160 $\mathrm{km} / \mathrm{h}$ design speed. It is expected to use in $200 \mathrm{~km} / \mathrm{h}$ design speed prospectively as in the Ejpovice tunnel (Metroprojekt). An enterance of Turecký Vrch tunnel can be seen in Fig. 6. It is a one tube tunnel with two railway lines inside.

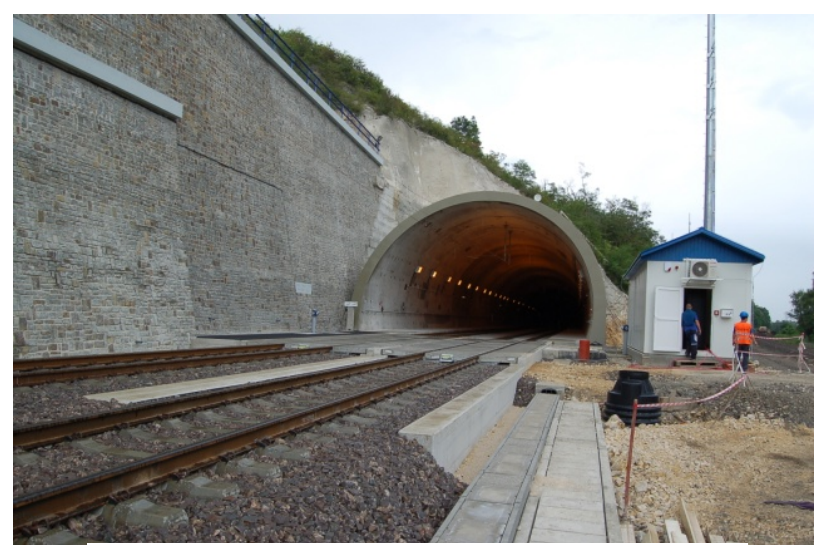

Fig. 6. An enterance of Turecký Vrch railway tunnel (Metroprojekt)

Some other tunnels which are under construction in Slovakia are Milochov tunnel and tunnel Diel which have $1082 \mathrm{~m}$ and $1861 \mathrm{~m}$ length respectively (Annual Report, Zelenice Slovenskej Republiky, 2020). They are constructed also with NATM (Zelenice Slovenskej Republiky).

These tunnels were designed with the aim of modernisation of railway corridors in Europe. Each of them shortens the travel time with different durations on its railway.

\section{Impact of new tunnels to train operation}

General impact of new tunnels is connected to the reduction of riding time as well as travelling time from passengers' point of view. Ejpovice tunnel shorten the route length about 6 kilometres and the travelling time is about 11 minutes shorter than previous route. Ejpovice tunnel costs were about 280 million $€$ therefore the shortening score is almost 25 millions $€$ per 1 spared minute. Building of Ejpovice tunnel was a little bit controversial due to financing and delays as well as unpredictable technical and technology problems. There were not enough experiences with tunnels with this length and modern technology in the Czech Republic yet.

Tunnel Turecký Vrch in Slovakia was built as a part of modern corridor main railway line from Bratislava to Žilina but its impact to travelling time is very limited. It was built mostly due to environmental reasons such as noise and animal corridors near this area. On the same railway line, there is a new tunnel Diel near Púchov, which has very positive impact to travelling time. System of these tunnels on mentioned railway line enables to use the maximum speed of $160 \mathrm{kph}$ in the whole section, what significantly shorten the whole travel from Bratislava to Žilina and vice versa.

\section{Conclusions}

1. One of the tunnel construction methods is NATM and it has some important points due to tunnel excavation and bearing capacity of excavation support system.

2. There are some tunnels which are still under construction and already constructed by NATM as a result of modernisation of existing railway roads to shorten the travel time.

3. New tunnels were built and some are already in construction in the Czech Republic as well as Slovakia. These tunnels have various direct impact to train operation such as reduction of riding time and travelling time.

4. New tunnels have also indirect positive impacts, mostly to environment, for example reduction of noise or animal corrdiors without any barriers.

5. Particular impacts of new tunnels to train operation as well as their construction method are mentioned in the text above.

\section{References}

Aygar, E.B., Gokceoglu, C. 2020 Problems encountered during a railway tunnel excavation in squeezing and swelling materials and possible engineering measures: a case study from Turkey. Sustainability 12:1166. doi:https:// doi. org/10. 3390/ su120 31166

Xu L., Huang H.W. 2004 Time effects in rock- support interaction: a case study in the construction of two road tunnels, International Journal of Rock Mechanics and Mining Sciences, Volume 41, Supplement 1, Pages 888-893, ISSN 1365-1609, https://doi.org/ 10.1016/j.ijrmms.2004.03.153.

Rabcewicz L. 1964 The New Austrian Tunnelling Method, Part one, Water Power, November 1964, 
453-457, Part two, Water Power, December $1964,511-515$

Rabcewicz L. 1965 The New Austrian Tunnelling Method, Part one, Part Three, Water Power, January 1965, 19-24.

Rabcewicz L. \& Golser J. 1973 Principles of dimensioning the supporting system for the "New Austrian Tunnelling Method", Water Power, March 1973, 88-93.

Karakus, Murat \& Fowell, R. 2004 An insight into the New Austrian Tunnelling Method (NATM) ROCKMEC'2004-7th Regional Rock Mechanics Symposium, Sivas, Türkiye.

Marek M. et al. Steel fiber reinforced concrete precast tunnel segments: design using nonlinear analysis Online:

https://www.cervenka.cz/assets/files/article/\%C4\%8 Dl\%C3\%Alnek_aplik ace_tunel_ejpovice.pdf

Network Statement on Nationwide and Regional Railways Valid for the Preparation of the Timetable 2022 and the Timetable 2022 in forceas of 11.12. 2020 Ref. No. 80929/2020-SŽ-Ǧ̌-O5

Online:https://www.spravazeleznic.cz/documents/50 007830/124638401/Prohl\%C3\%A1\%C5\%A1en\%C $3 \% \mathrm{AD}+2022$ en_web. pdf/686f390a-6c42-4557$9756915 \mathrm{c} 2 \mathrm{f} 4 \mathrm{~d} 64 \mathrm{af}$

Annual Report 2020, Sprava Zeleznice, Czech Republic Online:https://www.spravazeleznic.cz/doc uments/ 50007830/51603047/Annual+report+2020/4cf14d13 -e766-4c6b-9dbf-5b181a36b10c

Metroprojekt, Online: https://www.metroprojekt.cz/ en/home/tunnels-and-other-undergroundconstructions/the-turecky-vrch-railway- tunnel

Annual Report 2020, Zelenice Slovenskej Republiky Online:https://www.zsr.sk/files/o-nas/vyrocnespravy/annualreport2020.pdf

Zelenice Slovenskej Republiky Online: http://www.zsr.sk/slovensky/mediaroom/vyjadrenia-pre-media- 2017/marec/zsrmodernizacia-tunel-milochov-tuneldiel.html?page_id=5282 